\title{
The lesser of two evils: a qualitative study of quetiapine prescribing by family physicians
}

\author{
Martina Kelly MBBCh MA, Tim Dornan MD PhD, Tamara Pringsheim MD MSc
}

\section{Abstract}

Background: Quetiapine is an antipsychotic that is widely prescribed off-label by family physicians despite evidence that safer alternatives exist. The aim of this research was to explore, in-depth, family physicians' reasons for this behaviour.

Methods: We conducted qualitative interviews with 15 urban family physicians in Alberta between October 2015 and April 2016 . Participants were purposively selected based on sex, years of experience and practice type. Interviews explored participants' experiences prescribing quetiapine. Interviews were recorded, transcribed verbatim and coded with the use of thematic analysis.

Results: A wish to support day-to-day function of patients with complex psychosocial needs without causing benzodiazepine addiction motivated participants to prescribe quetiapine. The indications were varied and included incomplete symptom resolution, unclear or multiple mental health diagnoses, and complicated psychosocial problems. Family physicians benchmarked their prescribing against peers and were reluctant to stop medication started by colleagues. Limited knowledge of quetiapine's adverse effects led prescribers to choose low dosages.

Interpretation: Quetiapine helped family physicians treat patients with complex mental health problems without prescribing benzodiazepines, but awareness of quetiapine's adverse effects was poor. Education about quetiapine should combine psychopharmacology with multidisciplinary educational initiatives that focus on symptom resolution, comorbidity and nondrug options to promote more appropriate prescribing.

uetiapine is the most widely prescribed antipsychotic in North America. ${ }^{1,2}$ In 2008, antipsychotic drugs became the top-selling drug class in the United States, with estimated sales of US\$14.6 billion., Global antipsychotic sales in 2010 were US\$25.4 billion; of these, Seroquel (quetiapine) was the fifth highest selling pharmaceutical worldwide, costing an estimated US\$6.8 billion. ${ }^{4}$ In Canada, prescriptions for quetiapine rose by $300 \%$ between 2005 and 2012. Using the IMS Brogan Canadian CompuScript databases to identify prescribing data, researchers found that $50 \%$ of filled antipsychotic prescriptions in Canada were for quetiapine, and most came from family physicians. ${ }^{2}$ Although quetiapine is licensed for the treatment of schizophrenia and bipolar disorder and as an adjunctive to antidepressants in moderate to severe depression, much prescribing of quetiapine is offlabel. ${ }^{2,5}$ Off-label prescribing of antipsychotics has been studied extensively, including a meta-analysis of 170 studies. $^{6}$ Leslie and colleagues ${ }^{7}$ examined prescribing data from the US Department of Veteran Affairs and found that $60.2 \%$ of the 279778 patients who received a prescription for an antipsychotic in 2007 had no indication for its licensed use; of these, $43 \%$ were prescribed quetiapine. More recently, researchers in the United Kingdom examined prescribing data using The Health Improvement Network, a primary care database of almost 10 million patients. ${ }^{5}$ They found that only $36 \%(n=4824)$ of those prescribed quetiapine had a serious mental illness recorded. Insomnia, anxiety and behavioural disturbance in elderly people and children are common reasons for off-label use. ${ }^{3,6,8}$ Evidence of benefit for these indications is disputed. ${ }^{6,9,10}$ Adverse metabolic, neurologic and cardiovascular effects ${ }^{9,11}$ pose a significant risk of harm. ${ }^{11,12}$ Maglione and colleagues ${ }^{6}$ calculated a number needed to harm of 8 (odds ratio 5.16, 95\% confidence interval 2.93-9.51) for neurologic adverse effects in patients with dementia and of 16 (odds ratio 2.72, 95\% confidence interval 2.07-3.56) for weight gain and increased appetite in other conditions.

Competing interests: None declared.

This article has been peer reviewed.

Correspondence to: Martina Kelly, makelly@ucalgary.ca

CMAJ Open 2018. DOI:10.9778/cmajo.20170145 
Several professional bodies, including the Canadian Psychiatric Association, ${ }^{13}$ the American Psychiatric Association, ${ }^{14}$ the American Diabetes Association ${ }^{15}$ and the American Geriatrics Society, ${ }^{16}$ caution physicians to use antipsychotics judiciously. ${ }^{14-16}$ The Choosing Wisely campaign made 4 recommendations for restricting the use of second-generation antipsychotics, in particular to avoid their use for insomnia (in any age group) and behavioural disturbance, particularly in patients with attention deficit hyperactivity disorder or dementia. ${ }^{17}$ Guidelines on deprescribing of antipsychotics were recently published. ${ }^{18,19}$

Decisions to prescribe are not simply a matter of knowing the indications for drugs. Decisions are influenced by characteristics of patients ${ }^{20}$ and practitioners, ${ }^{21-24}$ the organizational settings in which physicians work, ${ }^{25,26}$ commercial influences $^{23,27}$ and interactions among these factors. Continuing professional development is a means of influencing prescribing behaviour, but this calls for a clear understanding of the complex web of factors that cause questionable behaviours to exist and persist. The exploratory nature of qualitative research is well suited to scratching below the surface of nonideal behaviours and identifying obstacles and facilitators to the adoption of desired behaviours. We therefore performed a qualitative study to explore in depth why and how family physicians prescribe quetiapine.

\section{Methods}

This interview study was set in an urban family practice in Alberta. The researchers were a female family physician interested in mental health (M.K.), a female neurologist with an interest in pharmacoepidemiology and mental health (T.P.) and a male endocrinologist working in medical education research (T.D.). All have experience in conducting qualitative research.

\section{Sampling and recruitment}

We disseminated study information comprising an introductory email, cover letter and informed consent via faculty email lists (Department of Family Medicine, University of Calgary). We contacted those interested by telephone to give more information, answer questions, ensure anonymity and arrange an interview. We informed participants that the study objective was to explore family physician use of quetiapine and gain a better understanding of prescribing practices.

We constructed a sampling frame to obtain a purposive sample by sex, years of experience and practice type. Use of the sampling frame enabled us to track participant characteristics to ensure we interviewed physicians with a range of experience. Initially, an overrepresentation of experienced physicians volunteered, so we stopped recruiting from that group and focused on more recent graduates and physicians working in walk-in clinics. Sampling in the later stages was influenced by the findings of interim analysis.

\section{Data collection}

To minimize any social desirability bias that might result from group interaction and to ensure that physicians felt com- fortable providing in-depth descriptions of their prescribing practices, we conducted one-on-one interviews to collect data. Two of the investigators (M.K. and T.P.) conducted interviews in person (13 interviews) or by telephone ( 2 interviews), for which they offered participants a \$250 honorarium. Three participants were known to M.K. and 1 was known to T.P. through professional interactions; none were known in a personal capacity.

We developed and piloted a semistructured interview guide. One of the investigators (M.K.) sent an initial version of the guide to 6 family doctors in her clinic for feedback. She then conducted a pilot interview with 2 colleagues and amended the guide. These interviews did not contribute to the final data set. The interviewer opened by asking the participant to describe his or her clinical practice and general approach to patients with mental health concerns. Participants then described their experiences of prescribing quetiapine. We followed up issues they raised and asked additional questions about patterns of quetiapine use, resources, prescribing influences and patient factors. The final interview guide is available in Supplementary Table S1, Appendix 1 (available at www.cmajopen.ca/content/6/2/E191/suppl/DC1). Interviews were conducted between October 2015 and April 2016.

\section{Data analysis}

Data collection and analysis were iterative and were used to inform ongoing sampling and to modify the interview. Interviews were recorded, transcribed and coded with the use of template analysis. This is a flexible form of thematic analysis ${ }^{28}$ in which an initial template is devised based on a priori codes developed from the literature. The template is then modified in response to open coding of transcripts. Transcripts were read independently and initial codes identified. Two investigators (M.K. and T.P.) met repeatedly to discuss and refine the preliminary template. They then applied the template to further data and refined it progressively until they arrived at a final template, over the course of 8 meetings. To prevent the findings being unduly influenced by their individual preconceptions, they discussed their responses to the data and recorded field notes after each meeting to capture their different perspectives as generalist and specialist physician, respectively. A senior physician (T.D.) experienced in qualitative prescribing research promoted researcher reflexivity, through discussion and by challenging the interpretation, during the initial phase of analysis, midway and at its final stage. Analysis continued until data saturation was reached, with no new themes emerging from latter interviews.

We gauged the trustworthiness of our findings by sending our final template and draft paper to all participants as a form of member checking. Four participants responded and agreed with the findings. In addition, we presented findings at 3 family medicine conferences (provincial, national and international).

\section{Ethics approval}

This study received ethics approval from the Conjoint Health Research Ethics Board, University of Calgary. 


\section{Results}

Fifteen physicians ( 8 men and 7 women) participated (Table 1). No one who contacted the study team declined interview. Interviews lasted 29-66 (average 40) minutes and were conducted in locations determined by the participants, which included their practices or homes, coffee shops or the researchers' offices. Twelve participants worked as family

\begin{tabular}{|lc|}
\hline Table 1: Characteristics of participants & \\
\hline Characteristic & $\begin{array}{c}\text { No. (\%) of } \\
\text { participants } \\
n=15\end{array}$ \\
\hline Male sex & $8(53)$ \\
\hline Years in practice & $1(7)$ \\
\hline$<5$ & $4(27)$ \\
\hline $5-9$ & $4(27)$ \\
\hline $10-14$ & $6(40)$ \\
\hline$\geq 15$ & $6(40)$ \\
\hline Practice type & $4(27)$ \\
\hline \begin{tabular}{l} 
Community family practice (general) \\
\hline $\begin{array}{l}\text { Community family practice (vulnerable/inner } \\
\text { city population) }\end{array}$
\end{tabular} \\
\hline \begin{tabular}{l} 
Walk-in clinic \\
\hline $\begin{array}{l}\text { Family doctor working in hospital } \\
\text { (hospitalist) }\end{array}$
\end{tabular} \\
\hline $\begin{array}{l}\text { Access to extended mental health services in } \\
\text { community or hospital }\end{array}$ \\
\hline
\end{tabular}

physicians in the community, and 3 were family physicians working full-time (2) or part-time (1) as hospitalists. Four participants worked in clinics designed to support patients with complex psychosocial needs such as chronic mental illness, low income, unemployment and homelessness. Most participants worked in extended primary care teams, which included behavioural health consultants (13 participants), social workers (6) and joint physician-psychologist appointments (3).

Our final template, which details themes and subthemes that summarize participants' use of quetiapine, is shown in Supplementary Table S2, Appendix 1. This narrative elaborates those themes. Further exemplar quotations are provided in Supplementary Table S3, Appendix 1.

Participants were torn between feeling responsible for relieving patients' symptoms so they could function in society and giving them benzodiazepines, to which they might become addicted. Quetiapine seemed to balance efficacy against safety (Figure 1).

\section{"Mental health plus": A solution for patients with complex psychosocial needs?}

Participants did not see quetiapine as a first-line treatment for depression, anxiety, behavioural disorders or insomnia. They reserved it for patients unresponsive to first-line therapies, those with multiple psychiatric diagnoses, or those with challenging psychological or social histories. Quetiapine was able to "calm," "take the edge off" or "settle" agitated or distressed patients. One physician described this as "mental health plus." The decision to use quetiapine was based on physicians' belief that it relieved distressing symptoms and helped patients retain some semblance of normality - be it to remain able to work, take care of their families or keep their hostel bed (Table 2, quotations 1-4).

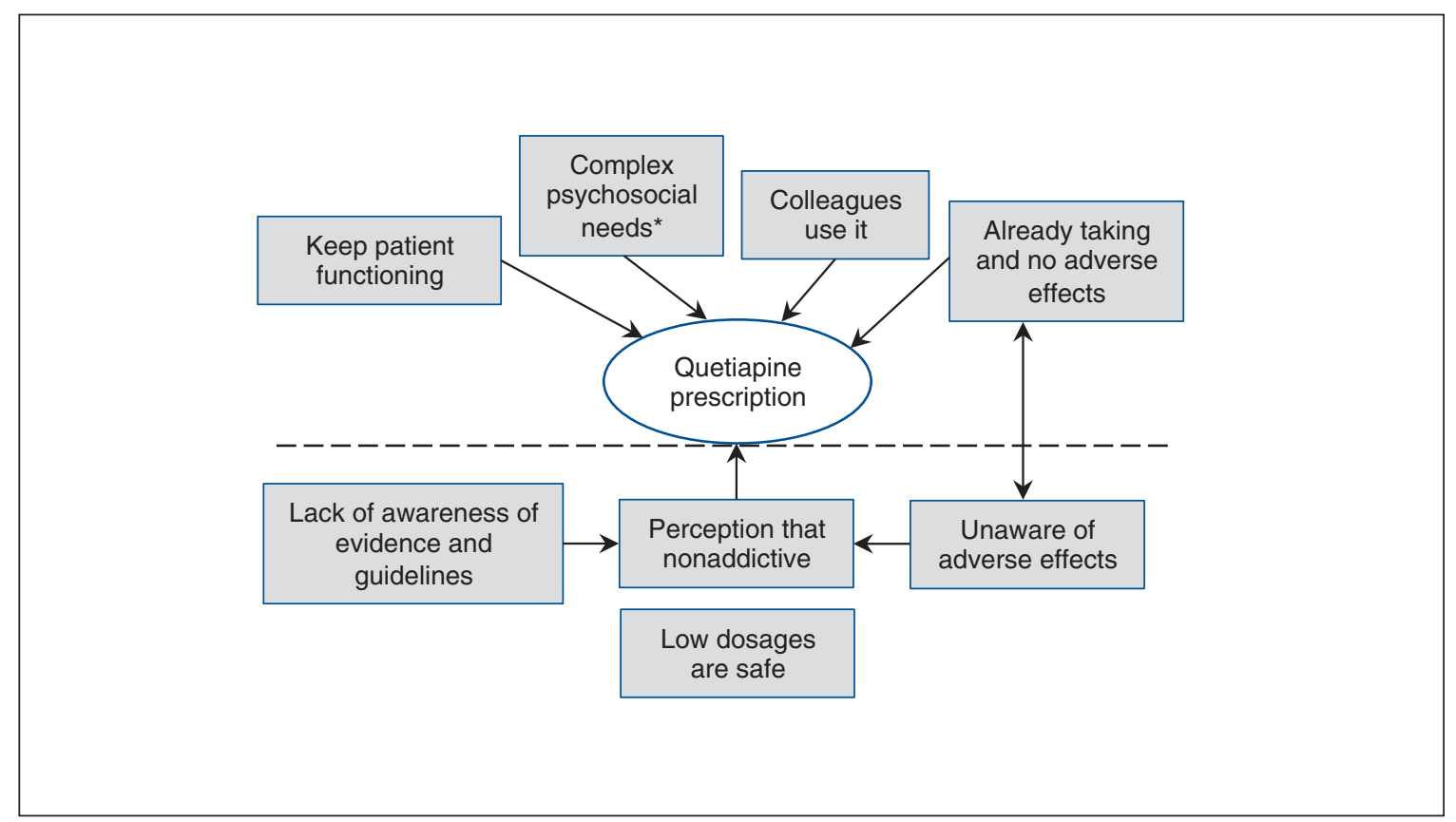

Figure 1: Influences that promote off-label use of quetiapine. *Patients with complex psychosocial needs have incomplete symptom resolution with a single agent, have multiple mental health diagnoses and may live in unstable environments. 
Table 2: Themes and illustrative quotations

\begin{tabular}{|c|c|c|}
\hline Theme & $\begin{array}{c}\text { Quotation } \\
\text { no. }\end{array}$ & Illustrative quotation \\
\hline \multirow[t]{4}{*}{$\begin{array}{l}\text { "Mental health } \\
\text { plus" }\end{array}$} & 1 & $\begin{array}{l}\text { So most of us family docs are used to using zopiclone for sleep, and so the reason, I } \\
\text { think, I think l'm seeing so much quetiapine is because there's another psychiatric } \\
\text { aspect to what they're seeing, so it's not just sleep. ... There's either an anxiety } \\
\text { component, an agitation component, there's something else. It's sleep plus. (Female } \\
\text { part-time hospitalist, 5-9 yr in practice) }\end{array}$ \\
\hline & 2 & $\begin{array}{l}\text { I would see patients who I guess were primarily coming out of jail and a lot of those } \\
\text { patients would be on quetiapine for aggressive behaviour, for sleep, for anxiety, and } \\
\text { some of them would even say, some of those patients would say that it helped them sort } \\
\text { of quell their addictions, so that's probably where I got exposed to it the most. (Male, } \\
\text { full-time community practice, vulnerable populations, 5-9 yr in practice) }\end{array}$ \\
\hline & 3 & $\begin{array}{l}\text { Mhm, so a patient comes in with, so middle-aged patient, either female or male, coming } \\
\text { in with predominantly generalized anxiety, some depressive features, some insomnia, } \\
\text { who is suffering most acutely from the insomnia and the fatigue as a result, which then } \\
\text { ends up fuelling the anxiety and depressive symptoms, so would then start at a low } \\
\text { [dosage] concurrently an antidepressant in addition to very low [dosage], say } 12.5 \mathrm{mg} \text {, } \\
\text { of quetiapine at night just to help with the sleep initiation. (Female, community practice, } \\
5-9 \text { yr in practice) }\end{array}$ \\
\hline & 4 & $\begin{array}{l}\text { On the other hand, that's one complaint that I think we struggle with addressing, } \\
\text { because you just don't have a lot of options that actually are reliably effective and don't } \\
\text { come with a host of other problems, so there's certainly been times where I think we've } \\
\text { prescribed quetiapine just as a sleeping aid simply because we don't want to prescribe } \\
\text { anything else and the encounter is not going to end, you know, we sort of have to give } \\
\text { up a prescription for that in order to meet other goals, so some negotiation where, sort } \\
\text { of, picking at a bit of a battle with the patient that might not be very therapeutic over that } \\
\text { issue. There may be other things that we're working on as a priority. (Male, community, } \\
\geq 15 \mathrm{yr} \text { in practice) }\end{array}$ \\
\hline \multirow[t]{2}{*}{$\begin{array}{l}\text { Choosing } \\
\text { cautiously: the } \\
\text { lesser of } 2 \text { evils }\end{array}$} & 5 & $\begin{array}{l}\text { You need to stay away as much as possible from benzodiazepines or zopiclone or } \\
\text { anything in that class because of the addictive properties and, well, dependence, really } \\
\text { and the interference with sleep architecture. Now, admittedly, I don't fully understand } \\
\text { how quetiapine either augments or disrupts sleep architecture, so that I don't know. I } \\
\text { don't know anything about the long-term effects, but as a result of us needing to move } \\
\text { away from [benzodiazepines] etc., it seems like quetiapine has moved into that vacuum } \\
\text { that was created. (Female, community practice, vulnerable populations, 5-9 yr in } \\
\text { practice) }\end{array}$ \\
\hline & 6 & $\begin{array}{l}\text { No. No, I think because there [are] not any alternatives, right? It's sort of, like, what do } \\
\text { you do with somebody who's got a personality disorder, has impulsivity, has addictions, } \\
\text { has anger management problems, and you don't want to put them on a benzodiazepine, } \\
\text { right? Like, there's not a lot of other options. (Male, full-time community, vulnerable } \\
\text { populations, } 10-14 \text { yr in practice) }\end{array}$ \\
\hline $\begin{array}{l}\text { My patients are fine } \\
\text { on low dosages }\end{array}$ & 7 & $\begin{array}{l}\text { They seem to do fine, so l'm not very worried about } 50 \text { or } 100 \text { [mg]. I'm embarrassed to } \\
\text { admit, I'm not even sure about the relationship between quetiapine and diabetes, so if } \\
\text { they've had some blood tests, I check and see what their blood glucose is, and } \\
\text { obviously take a look at their weight, but I don't routinely check blood glucose after } \\
\text { they've been on it for a while. (Male, full-time community practice, } \geq 15 \text { yr in practice) }\end{array}$ \\
\hline \multirow[t]{3}{*}{$\begin{array}{l}\text { Prescribing } \\
\text { influences }\end{array}$} & 8 & $\begin{array}{l}\text { If I were to hazard a guess, it would be, if it's becoming more popular, that it would be } \\
\text { just something that you're seeing your colleagues using and you're seeing specialists } \\
\text { using, so you tend to use it a bit more. (Female, full-time community, 10-14 yr in } \\
\text { practice) }\end{array}$ \\
\hline & 9 & $\begin{array}{l}\text { I've renewed it in patients who have had it for awhile and they're stable on their } \\
\text { medications, I certainly renew it, though, when I do, I ask why they're taking the } \\
\text { medication, and oftentimes they don't really know why they're on it. (Male, full-time } \\
\text { community practice, 5-9 yr in practice) }\end{array}$ \\
\hline & 10 & $\begin{array}{l}\text { I do tend to just continue. I think the only time that I would necessarily reevaluate, I } \\
\text { reevaluate their mood on a regular basis, but I think the only time that I would reevaluate } \\
\text { their medications is if their mood was not as good as we would like it to be. I've had } \\
\text { patients who have been on it a long time, and they are counselled by me on the risks of } \\
\text { staying on it long-term, and they say, "Doctor, I want it, it helps me sleep and I feel better } \\
\text { and my mood is better," and I, they accept the risk and they want to stay on it. (Female, } \\
\text { community practice, 5-9 yr in practice) }\end{array}$ \\
\hline
\end{tabular}




\section{Choosing cautiously: the lesser of $\mathbf{2}$ evils}

Participants selected quetiapine because of its nonaddictive nature and because they felt it was less likely to be abused. They wanted to avoid benzodiazepines, so quetiapine was "the lesser of 2 evils" (male full-time hospitalist, 5-9 yr in practice) (Table 2, quotations 5 and 6).

\section{"My patients are fine on low dosages"}

Participants were unfamiliar with quetiapine's mechanism of action and knew variable amounts about its adverse effects. Most expressed belief that it was a reasonably safe option and were comfortable prescribing it at a dosage of $25-50 \mathrm{mg}$ per day. Since they thought this was safe, they did not monitor patients for adverse effects (Table 2, quotation 7). Few participants informed patients that quetiapine was an antipsychotic, and, if they did, they couched it as "not being used for that" and emphasized that the dosage was low.

\section{Prescribing influences}

Other physicians, such as psychiatrists, colleagues in family medicine and preceptors were the people who most often guided participants toward using quetiapine. Participants did not identify messaging from pharmaceutical companies or demand from patients as important prescribing influences (Table 2, quotations 8-10).

Caring for patients using quetiapine initiated by another physician created dilemmas. Participants usually continued prescriptions initiated in hospital, particularly if started by a psychiatrist, although they did not always know who had started it or why. When another family physician had started quetiapine, participants did not routinely reevaluate its use before renewing the prescription. Some participants said that patients were reluctant to stop quetiapine, and, since it seemed to provide therapeutic benefit, they chose to continue it (Table 2, quotation 10).

\section{Interpretation}

Family physicians' quetiapine prescribing was much less paradoxical, at the level of the individual physician and patient, than evidence at an epidemiological level suggested. ${ }^{3,8}$ Physicians and patients were between a rock and a hard place: treatment-resistant mental illness versus benzodiazepine addiction. Participants perceived low-dosage quetiapine as relatively safe and effective, and they were under the impression that fellow family physicians and psychiatrists thought the same. Widespread prescribing of quetiapine for off-label indications could too easily give the impression of indiscriminate use: participants in this study felt they prescribed quetiapine carefully, taking account of patients' symptoms and social situations. Their knowledge, however, of the mechanism of action of quetiapine, its adverse effects and the need for monitoring was poor. None of our participants had a system in place to monitor patients taking quetiapine; this was compounded by their lack of knowledge as to what adverse effects to look for. This knowledge gap contributed to the preferential use of quetiapine over other drugs and likely a failure to recognize and properly attribute quetiapine-induced adverse effects to the drug. Ongoing prescribing of quetiapine was perpetrated by an assumption among hospitalists, family physicians and psychiatrists that patients were prescribed quetiapine for clear indications, but these were poorly communicated. Hospital doctors expected family doctors to know when to stop quetiapine, yet the latter were reluctant to discontinue psychotropic medications for fear of causing mental distress or relapses. Patients were seldom informed that the medication they were prescribed was an antipsychotic.

These findings resonate with previous prescribing studies indicating that physicians' prescribing decisions are strongly affected by personal experience, ${ }^{21,23,24}$ social influences and health care systems..$^{22,29}$ The role of social factors in influencing the implementation of Choosing Wisely recommendations, ${ }^{17}$ particularly prescribing recommendations, is supported by a recent survey of family physicians and primary care workers in the US. ${ }^{20}$ Notably, the recommendations that health care workers felt would be the most problematic related to caring for symptomatic patients, because of a potential negative impact on the doctor-patient relationship. In our study, family physicians negotiated the use of quetiapine, balancing immediate symptoms with other priorities.

A key benefit of quetiepine identified by our participants was its calming effect. Family physicians perceived the drug as a safe, effective alternative to potentially addictive medication. ${ }^{1}$ Quetiapine appeared to fill the niche previously occupied by benzodiazepines. ${ }^{30}$ Yet our participants' knowledge of the mechanism of action of quetiapine and safety concerns was limited, despite recent educational campaigns. ${ }^{14,16}$ Family physicians mitigated this gap through the use of low dosages and, in keeping with previous literature on guideline use, ${ }^{31,32}$ prioritized real-world experience by colleagues - both peers and specialists - over information. Ambivalent attitudes and perceptions have been identified as important determinants of inappropriate prescribing. ${ }^{33}$ A recent initiative that incorporated behaviour-change techniques tailored to prescriber characteristics using e-learning showed increased adherence with guidelines, reduced prescribing and increased use of psychosocial interventions by family physician trainees. ${ }^{34}$

\section{Strengths and limitations}

One strength of our study is the use of qualitative methods to explore family physicians' experiences with quetiapine. This allowed participants to detail their prescribing of quetiapine, which enabled us to investigate what they said they did rather than their opinions of what they should do. Their frankness and willingness to admit ignorance gave us confidence in the validity of their accounts of their practices. Our complementary perspectives of family physician and specialist helped us both understand and challenge each other during the analysis.

This was an exploratory study, and our sample consisted of physicians from a single urban centre. We continued interviewing until our analysis achieved data saturation. Although 4 of our participants worked with vulnerable populations, all of our participants described quetiapine use for patients with complex psychosocial needs. Although our study design was in 
line with qualitative research practice, a more exhaustive sample size might have added extra insights. Finally, it is possible that participants may have felt some imperative to please us, as physician colleagues, in their responses.

\section{Conclusion}

This qualitative study provides insights into family physicians' reasons for prescribing quetiapine. Although quetiapine was not used as a first-line treatment for mental disorders, it was commonly prescribed as an adjunct, particularly to sedate anxious patients or those experiencing sleep difficulty. This practice was justified, in the eyes of participants, through the use of low dosages and by the fact that it was common practice by colleagues. However, participants were ill informed on how quetiapine worked, its adverse effects and the need for ongoing monitoring. Our findings point to an urgent need for increased education about quetiapine. Such initiatives should focus on increasing knowledge and addressing the psychological dynamics of prescribing, such as attitudes, perceptions and self-efficacy, to promote safe prescribing. Further research is needed to understand why, with resources in hand, physicians felt pressure to choose between the lesser of 2 evils, both of which were classes of drugs, when psychological therapies were available. Additional research to understand patients' perspectives on the use of quetiapine would be useful to help guide physicians in their conversations with patients.

\section{References}

1. Kuehn BM. Questionable antipsychotic prescribing remains common, despite serious risks. FAMA 2010;303:1582-4.

2. Pringsheim T, Gardner DM. Dispensed prescriptions for quetiapine and other second-generation antipsychotics in Canada from 2005 to 2012: a descriptive study. CMA7 Open 2014;2:E225-32.

3. McKean A, Monasterio E. Off-label use of atypical antipsychotics. CNS Drugs 2012;26:383-90.

4. Monasterio E, McKean A. Quetiapine use: Science or clever marketing? Aust NZ7 Psychiatry 2013;47:96-7.

5. Marston L, Nazareth I, Petersen I, et al. Prescribing of antipsychotics in UK primary care: a cohort study. BM7 Open 2014;4:e006135.

6. Maglione M, Maher AR, Hu J, et al. Off-label use of atypical antipsychotics: an update. Report no 11-EHC087-EF. Rockville (MD): Agency for Healthcare Research and Quality; 2011.

7. Leslie DL, Mohamed S, Rosenheck RA. Off-label use of antipsychotic medications in the Department of Veterans Affairs health care system. Psychiatr Serv 2009;60:1175-81.

8. Duncan D, Cooke L, Symonds C, et al. Quetiapine use in adults in the community: a population-based study in Alberta, Canada. BMF Open 2016;6:e10861.

9. Carney AC. Efficacy of quetiapine off-label uses: data synthesis. 7 Psychosoc Nurs Ment Health Serv 2013;51:11-8.

10. Walton SM, Schumock GT, Lee KV, et al. Prioritizing future research on offlabel prescribing: results of a quantitative evaluation. Pharmacotherapy 2008;28: 1443-52.

11. Muench J, Hamer AM. Adverse effects of antipsychotic medications. Am Fam Physician 2010;81:617-22.

12. Katzman MA, Bleau $\mathrm{P}$, Blier $\mathrm{P}$, et al. Canadian clinical practice guidelines for the management of anxiety, posttraumatic stress and obsessive-compulsive disorders. BMC Psychiatry 2014;14(Suppl 1):S1.

13. Urness D, Parker NJ, Rapoport MJ, et al. Choosing Wisely: wise choices in psychiatry. Can 7 Psychiatry 2016;61:700-4.

14. Reus VI, Fochtmann LJ, Eyler AE, et al. The American Psychiatric Association practice guideline on the use of antipsychotics to treat agitation or psychosis in patients with dementia. Am 7 Psychiatry 2016;173:543-6.

15. American Diabetes Association, American Psychiatric Association, American Association of Clinical Endocrinologists, North American Association for the Study of Obesity. Consensus development conference on antipsychotic drugs and obesity and diabetes. Diabetes Care 2004;27:596-601.

16. AGS Choosing Wisely Workgroup. American Geriatrics Society identifies another five things that healthcare providers and patients should question. 7 Am Geriatr Soc 2014;62:950-60.
17. Canadian Academy of Child and Adolescent Psychiatry, Canadian Academy of Geriatric Psychiatry, Canadian Psychiatric Association. Thirteen things physicians and patients should question: Choosing Wisely Canada; 2017. Available: https://choosingwiselycanada.org/psychiatry/ (accessed 2018 Apr. 20).

18. Evidence-based deprescribing algorithm for antipsychotics. Kitchener $(\mathrm{ON})$ Ontario Pharmacy Evidence Network. Available: www.open-pharmacy-research. ca/evidence-based-deprescribing-algorithm-for-antipsychotics/ (accessed 2017 Sept. 1).

19. Tanni P, Dunbabin D. A guide to deprescribing antipsychotics. Tasmania (AU): Consultant Pharmacy Services, Primary Health Tasmania, PHN Tasmania; 2016. Available: https://www.primaryhealthtas.com.au/sites/default/ files/A\%20Guide\%20to\%20Deprescribing\%20Antipsychotics.pdf (accessed 2017 Sept. 1).

20. Zikmund-Fisher BJ, Kullgren JT, Fagerlin A, et al. Perceived barriers to implementing individual Choosing Wisely recommendations in two national surveys of primary care providers. $\mathcal{F}$ Gen Intern Med 2017;32:210-7.

21. Watkins C, Harvey I, Carthy P, et al. Attitudes and behaviour of general practitioners and their prescribing costs: a national cross sectional survey. Qual Saf Health Care 2003;12:29-34.

22. Hajjaj FM, Salek MS, Basra MK, et al. Non-clinical influences on clinical decision-making: a major challenge to evidence-based practice. $7 \mathrm{R} \mathrm{Soc} \mathrm{Med}$ 2010;103:178-87.

23. Jones MI, Greenfield SM, Bradley CP. Prescribing new drugs: qualitative study of influences on consultants and general practitioners. BM7 2001;323:378-81.

24. Armstrong D, Reyburn H, Jones R. A study of general practitioners' reasons for changing their prescribing behaviour. BMF 1996;312:949-52.

25. Teixeira Rodrigues A, Roque F, Falcão A, et al. Understanding physician antibiotic prescribing behaviour: a systematic review of qualitative studies. Int $f$ Antimicrob Agents 2013;41:203-12.

26. Rich EC. Barriers to Choosing Wisely in primary care: it's not just about "the money." 7 Gen Intern Med 2017;32:140-2.

27. Spurling GK, Mansfield PR, Montgomery BD, et al. Information from pharmaceutical companies and the quality, quantity, and cost of physicians' prescribing: a systematic review. PLoS Med 2010;7:e1000352.

28. King N, Cassell C, Symon G. Using templates in the thematic analysis of text. In: Cassell C, Symon G, editors. Essential guide to qualitative methods in organizational research. London (UK): Sage; 2004:256-70.

29. Sketris IS, Langille Ingram E, Lummis HL. Strategic opportunities for effective optimal prescribing and medication management. Can 7 Clin Pharmacol 2009;16:e103-25.

30. Brett J. Concerns about quetiapine. Aust Prescr 2015;38:95-7.

31. Hayward RS, Guyatt GH, Moore K, et al. Canadian physicians' attitudes about and preferences regarding clinical practice guidelines. CMA7 1997;156: 1715-23.

32. Soumerai SB, McLauglin TJ, Avorn J. Improving drug prescribing in primary care: a critical analysis of the experimental literature. Milbank $Q 1989 ; 67$ : 268-317.

33. Anderson K, Stowasser D, Freeman C, et al. Prescriber barriers and enablers to minimising potentially inappropriate medications in adults: a systematic review and thematic synthesis. BM7 Open 2014;4:e006544.

34. Creupelandt $\mathrm{H}$, Anthierens $\mathrm{S}$, Habraken $\mathrm{H}$, et al. Teaching young GPs to cope with psychosocial consultations without prescribing: a durable impact of an e-module on determinants of benzodiazepines prescribing. BMC Med Educ 2017;17:259.

Affiliations: Department of Family Medicine (Kelly), Cumming School of Medicine, University of Calgary, Calgary, Alta.; School of Medicine, Dentistry and Biomedical Sciences (Dornan), Queen's University, Belfast, Northern Ireland; Departments of Clinical Neurosciences, Psychiatry, Pediatrics and Community Health Sciences (Pringsheim), Cumming School of Medicine, University of Calgary, Calgary, Alta.

Contributors: Martina Kelly and Tamara Pringsheim conceived and designed the study, acquired, analyzed and interpreted the data, and drafted the manuscript. Tim Dornan provided feedback on recruitment, conduct of interviews and data analysis. All of the authors contributed to revising the manuscript for important intellectual content, gave final approval of the version to be published and agreed to be accountable for all aspects of the work.

Funding: This study was supported by the Addiction and Mental Health Strategic Clinical Network, Alberta Health Services, Edmonton.

Acknowledgement: The authors extend many thanks to Wayne Weston for his thoughtful feedback and encouragement.

Supplemental information: For reviewer comments and the original submission of this manuscript, please see www.cmajopen.ca/content/6/2/ E191/suppl/DC1. 